\title{
Energy environmental impact of functional units of a university building
}

\author{
João Pedro Panagassi Forte, ${ }^{1,}$, Vasco Rato ${ }^{2}$ \\ ${ }^{1}$ ISCTE-Instituto Universitário de Lisboa. Av. Forças Armadas, 1649-026 Lisboa, Portugal \\ ${ }^{2}$ ISCTE-Instituto Universitário de Lisboa, ISTAR-IUL, Av. Forças Armadas, 1649-026 Lisboa, Portugal
}

\begin{abstract}
This paper presents the results of a qualitative assessment of the environmental impact of a set of functional units of a university building, considering negative impacts such as the ones originated by energy, water and resource usage, as well as waste production, but also positive impacts like the ones that may be derived from teaching and learning and from research. This paper is focused on the energy -related environmental impacts which are the most significant. The assessment is performed for three evaluation scenarios: Two of these scenarios are based on the actual condition of the building facilities and its use patterns and differ from each other in the level of severity attributed to each impact criteria. The third scenario has as additional input the future condition of electric energy production through the installation of photovoltaic (PV) panels (which is in progress). According to the assessment carried out, the implementation of the PV panels may have an important contribution in reducing the environmental impact related to the use of the building.
\end{abstract}

\section{Introduction}

Environmental management is considered one of the most important, if not the most important, instruments for controlling, managing and encouraging sustainable development, and may be linked to different norms emanating from public authorities and regulatory agencies [1].

According to Rohrich [2], there are three main perspectives to sustainable development: the economic, the social and the environmental. This paper presents a research about this latter. As in most cases, the environmental management of a university presents several challenges. Among these, solid waste (organic, contaminant or recyclable), energy requirements, and usage of water and paper, may be highlighted. The establishment of an environmental policy is an important step to withstand these challenges. To Juliatto, Calvo and Cardoso [3], The universities stand out with a new perspective in search for solutions.

Thus, understanding the environmental management and sustainability in higher education institutions, starting with the scientific work, during the social activities, in the office functions of the universities become important, It is because the scientific creation which it becomes possible to form opinion at universities.

The propose to implant a environmental management system in universities is based in the Agenda 21, which establishes that the universities institutions have diverses responsibilities regarding the formation and influence of a society increasingly sustainable. However, to implant an environmental management system at university, it must have in mind that it is a highly complex organization, due to diversification of theirs activities and plans to the heterogeneous social environment which incorporates and the structural model which is used nowadays [4].

According this logic by thinking the universities as any other institution which works like a service provider, they should worry with all the main impacts caused in the environment and the society, which comes from their actions, activities and from all ones who in certain way are evolver with the activities of the institutions, whether direct or indirect activities with the institution [5].

Therefore, environmental impact assessments at universities is extremely important to measure the establishment of them as sources of knowledge and institutions, which worry with future questions.

\section{State of the Art}

Rocha [6], says that the foundation of the environmental impact assessment process were established in the United States between 1969 and 1970. This legal instrument provided for the principles of US environmental policy and required potential polluters to: identify environmental impacts; negative environmental effects of the proposal; the alternatives of action; relation between the use of environmental resources in the shortterm and the maintenance or improvement of their longterm standard and the clear definition of the possible compromises of environmental resources, in the case of implementation proposal. This was one of the first

\footnotetext{
Corresponding author: jota panagassi@hotmail.com
} 
models to control the environmental impact that an organization tried to use.

Regarding the concept of environmental impact, the term may vary according to the subject studied. According to the CONAMA Resolution [7], the following definition of environmental impact is established:

"Any change in the physical, chemical or biological properties of the environment caused by any form of substance or energy resulting from human activities that directly or indirectly affects:

I - The health, safety and well-being of the population; II - Social and economic activities;

III - The aesthetic and sanitary conditions of the environment;

IV - The quality of environmental resources. "

One of the ways that universities have adopted as a way of managing their impacts is compliance with the procedures and specifications of ISO 14001: 2015. This standard is defined as a set of steps and requirements for the organization or institutions to ensure wich one is environmental certificated, in order to ensure that all stakeholders with certified legislation have an appropriate EMS.

One of the reasons for the IHE to adopt this type of standard as a step-by-step process for a certification is that ISO 14001 [8], has as a fundamental requirement that the organization's environmental policy be:

"Appropriate the nature, scale, bearing, and negative environmental impacts of the organization; commitment to continuous improvement; Be committed to accord legal requirements; provide a framework for the establishment and analysis of environmental objectives and targets; be documented, implemented and maintained; be communicated to internal and external collaborators; and it is available to the public. "

However, for an Environmental Management System to be highly efficient, it will be necessary to search for increasingly complex and precise analyses, by showing results that previously could not be seen more comprehensively.

For Tauchen [9], a more specific analysis can show more precise information. Therefore, if it is possible to measure a certain type of environmental impact in a type of space (classroom, bathrooms, library, study rooms, among others), it is possible to obtain detailed data that, if analysed more superficially, they would be more difficult to identify. With this, more specific and precise actions can be determined in the remediation or in the control of the impacts which have been observed in that situation, always seeking continuous improvement.

Therefore, this article aims to show the importance of minimize a local impact can have good environmental performance for the university, in this case, the energy use.

\section{Methodology}

The study consists basically of two types of analysis: Quantitative and Qualitative. It focus on diagnosing the types of spaces, their areas and their respective impacts. Analysis factors were established for each impact, as will be seen below. In addition, indexes of analysis were also established: Total Environmental Impact (TEI) and Final Impact (FI). After the collection of these data, the FIs of all the spaces were compared and the most impacting space of all at the Ala Autónoma was discovered. Firstly, data were collected together with the institution regarding the impacts already used by the University's Environmental Management System (EMS).

After this collection, the most relevant ones were selected for the study area and defined according to the university's EMS. Below are the impacts raised. In addition to these, there is also its type, which can be considered negative or positive.

Table 1. Relation between impacts and types of impact.

\begin{tabular}{|l|l|}
\hline \multicolumn{1}{|c|}{ Impacts } & Type \\
\hline Energy usage & $\mathrm{N}$ \\
\hline Potable water consumption & $\mathrm{N}$ \\
\hline Resources and material usage & $\mathrm{N}$ \\
\hline New constructions & $\mathrm{N}$ \\
\hline $\begin{array}{l}\text { Conducting of intern and } \\
\text { extern events }\end{array}$ & $\mathrm{N}$ \\
\hline Waste management & $\mathrm{N}$ \\
\hline Research & $\mathrm{P}$ \\
\hline Teaching - Learning & $\mathrm{P}$ \\
\hline Extension activities & $\mathrm{P}$ \\
\hline
\end{tabular}

Ala Autónoma being one of the main buildings of the institution, it is constituted by 4 main floors, an underground parking and a terrace. Consisting by eight spaces: Technical zone, sanitary installations, auditorium, offices, classroom, Professor's Office, Cafeteria and Laboratory. 


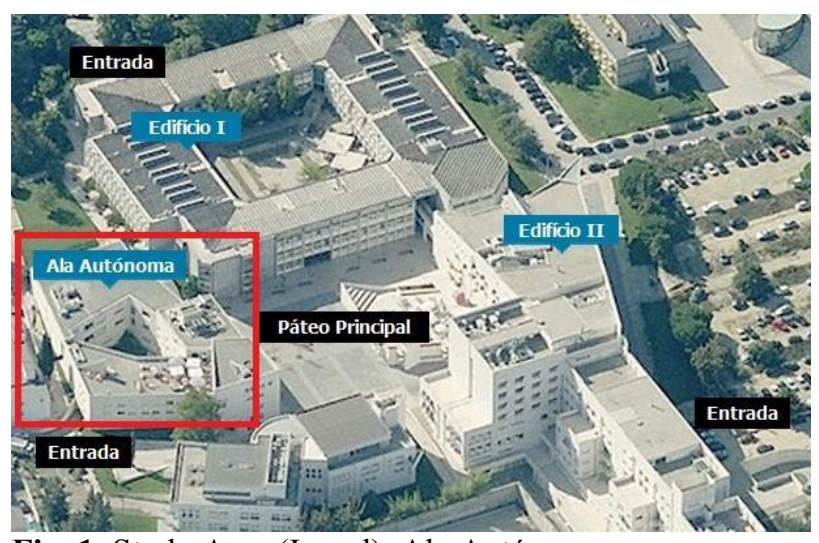

Fig. 1. Study Area (In red). Ala Autónoma

The focus of this study is to compare and define each space according to the classification used by the university itself to define the functionality of each location. 7

One of the important points after the definition of the spaces is the definition of their respective areas, to follow the next steps. Below we have the spaces and their respective areas.

Table 2. Study area and its spaces.

\begin{tabular}{|c|c|}
\hline \multicolumn{2}{|c|}{ Ala Autónoma } \\
\hline Spaces & Area $\left(\mathrm{m}^{2}\right)$ \\
\hline Technical Zone & 141 \\
\hline Sanitary Installations & 159,6 \\
\hline Auditorium & 250,7 \\
\hline Offices & 701,3 \\
\hline Classroom & 804,1 \\
\hline Professor's Office & 724,9 \\
\hline Laboratory & 307,5 \\
\hline Cafeteria & 15,1 \\
\hline Total & 2881,1 \\
\hline
\end{tabular}

In addition, analysis factors were also created for each selected impact, after which they were classified according to their intensity. In the end, seven analysis factors (Type, Mode, Magnitude, Duration, Reach, Effect and Reversibility) were established and all were classified through three different grades according to the intensity of the determined factor in that impact: $0.1-0.3$ -0.5 .

It is important to emphasize that the "type" factor does not have a score; this is because it is classified only in two ways, positive and negative, and not quantitative factors, like other factors.
Table 3. Factor description and scores.

\begin{tabular}{|c|c|c|}
\hline Factor & Analyse Factor & Score \\
\hline \multirow{2}{*}{ Type } & Positive & - \\
\hline & Negative & - \\
\hline \multirow{2}{*}{ Mode } & Direct & 0,5 \\
\hline & Indirect & 0,1 \\
\hline \multirow{3}{*}{ Magnitude } & Small & 0,1 \\
\hline & Intermediate & 0,3 \\
\hline & Large & 0,5 \\
\hline \multirow{3}{*}{ Duration } & Temporary & 0,1 \\
\hline & Cyclic & 0,3 \\
\hline & Permanent & 0,5 \\
\hline \multirow{3}{*}{ Outreach } & Local & 0,1 \\
\hline & Regional & 0,3 \\
\hline & Nacional/Internacional & 0,5 \\
\hline \multirow{3}{*}{ Effect } & Short & 0,1 \\
\hline & Intermediate & 0,3 \\
\hline & Long & 0,5 \\
\hline \multirow{2}{*}{ Reversibility } & Reversible & 0,1 \\
\hline & Irreversible & 0,5 \\
\hline
\end{tabular}

First, it is necessary to make the sum of these factors and, thus, obtaining the first index worked, the Total Environmental Impact (TEI) of each impact. Second, add the TEI of all impacts of a determined space and thus obtain the final TEI of the same.

Then, it will be necessary to multiply the TEI of the space by its respective area. This operation can be understood in the formula below. In this way, it will be possible to obtain the Final Impact (FI) of each space.

$\mathrm{FI}=\mathrm{TEI} \times$ Area $(1)$

Where Area represents the total area of each type of space [m2].

After that, it is necessary to compare the Final Impact of each space and, finally, to analyse which FI is the most representative in the comparison of all spaces. As an additional point for analysis, it is important to compare the TEIs of each impact, in order to define; also, what is the most significant impact of all. 


\section{Results}

In the site chosen as a form of analysis, some points may be important for the article, the first of them is the fact that the negative impacts are in greater quantity, standing out the electric use as the main impact. Below you will find all impacts analysed.

The impacts were divided between negative and positive. They are considered: Energy Use, Drinking Water Consumption, Use of Materials, Construction and Rehabilitation, Internal and Internal Events and Waste Management. The positives are Research, Teaching learning and University Extension.

When analysing the initial scenario, it is noticed that the most shocking space among all of them are the Common Rooms. As seen in the table below, it is possible to compare the spaces and, consequently, the FIs:

Table 4. Result of FI by space (Initial Scenario).

\begin{tabular}{|l|l|l|l|}
\hline \multicolumn{1}{|c|}{ Spaces } & TEI & Area & \multicolumn{1}{c|}{ FI } \\
\hline Technical Zone & $-6,3$ & 141,0 & $-888,3$ \\
\hline Professor's Office & $-0,5$ & 724,9 & $-362,5$ \\
\hline Classroom & $-3,1$ & 804,1 & $-2492,7$ \\
\hline Auditorium & $-3,6$ & 250,7 & $-902,5$ \\
\hline Sanitary Installations & $-8,8$ & 159,6 & $-1404,5$ \\
\hline Cafeteria & $-4,9$ & 15,1 & $-74,0$ \\
\hline Laboratory & 0,2 & 307,5 & 61,5 \\
\hline Offices & $-5,8$ & 701,3 & $-4067,5$ \\
\hline Ala Autónoma's Total & & 3104,2 & $-10130,5$ \\
\hline
\end{tabular}

Above, it is possible to notice that the FI of the whole building is $-10,130.5$, and that of all spaces analysed, the Common Room is the most striking (4067.5 ) of all, corresponding to almost $40 \%$ of the whole impact of the study area, together with the Classroom, the second most representative space, this value corresponds to $64.7 \%$ of the total FI.

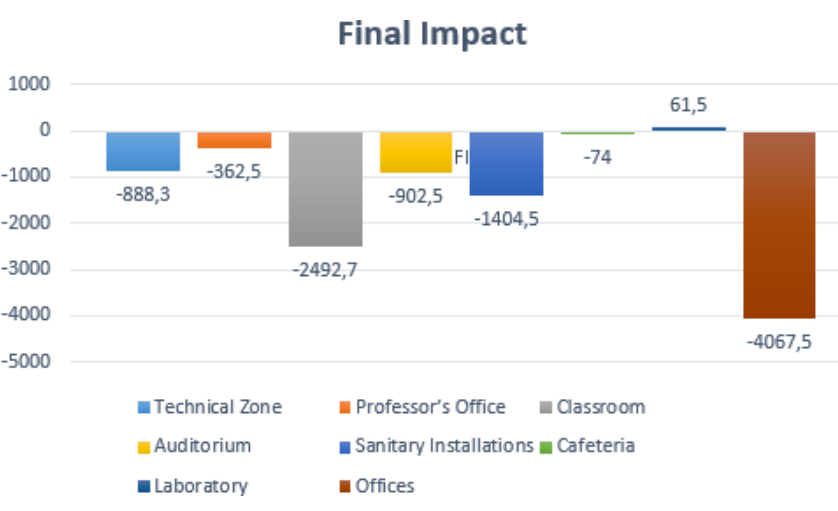

Fig. 2. Final Impact graph.
This graph is the representation of the table number 4. It is possible to identify all the areas analysed during this investigation and their Final Impact related, all the space was classified and they had the results in the graph. If the FI of all the spaces were added, the result will be the "Ala Autonoma's Total", which is $10.130,5$. This outcome shows that the building has a negative impact in the environment.

Another important fact analysed by the graph is the fact that the laboratory is the only space with positive impact in the institution. It happens due to the factors and impacts in this space are considerable positive.

According to the graph analysed, it is possible to understand how is difference of the Final Impact (FI) of the Officers in comparison with the others spaces. This area is responsible for a big amount of the Final Impact.

\subsection{Scenarios}

However, this type of analysis consists of qualitative factors that, even based on legal definitions, such as the CONAMA resolution mentioned above, there might still be variations in the ways in which the perception of each space is understood. Therefore, to analyse other forms of scenario becomes important, being created three different perspectives, three new scenarios. It is important the creation of these scenarios, because with more knowledge about different points of view, more realistic the analyse will become.

The first one is the Large Analyse scenario; its focus is to think more about the life cycle analysis of products that affect the classification of a certain environmental impact and its factors. Therefore, this type of analysis tends to be more rigid in relation to the classification of the impacts and factors of each space of the study area made previously, since the classification of each factor tends to take into consideration broader scales of analysis. The final table of analysis of the impacts of this scenario is presented:

Table 5. Result of FI by space (Large Analyze).

\begin{tabular}{|l|l|l|l|}
\hline \multicolumn{1}{|c|}{ Spaces } & TEI & Area & \multicolumn{1}{c|}{ FI } \\
\hline Technical Zone & $-6,9$ & 141,0 & $-972,9$ \\
\hline Professor's Office & 0,1 & 724,9 & 72,5 \\
\hline Classroom & $-3,3$ & 804,1 & $-2653,5$ \\
\hline Auditorium & $-3,9$ & 250,7 & $-977,7$ \\
\hline Sanitary Installations & $-9,4$ & 159,6 & $-1500,2$ \\
\hline Cafeteria & $-5,4$ & 15,1 & $-81,5$ \\
\hline Laboratory & $-0,4$ & 307,5 & $-123,0$ \\
\hline Offices & $-6,4$ & 701,3 & $-4488,3$ \\
\hline Ala Autónoma's Total & & 3104,2 & $-10724,8$ \\
\hline
\end{tabular}

It is clear that the Ala Autónoma's FI of this analysis is relatively larger, but the little difference to the value of the analysis of the initial scenario shows that, 
even taking into consideration the points cited in the paragraph above, the values are similar.

Another important point of this scenario is that the Classroom and the Common Room remain the most impacting spaces in the entire Ala Autónoma, corresponding to $66.5 \%$.

When analysing the next scenario (Short Analyse), it is realized that it was considered a smaller scale of observation, where the limit point of the analysis is based, at most, on scale in the impact with perceptible results. Therefore, the idea of analysing the life cycle in some impacts will not be considered as a great influence factor in the decisions of this scenario.

Table 6. Result of FI by space (Short Analyze).

\begin{tabular}{|l|c|c|c|}
\hline \multicolumn{1}{|c|}{ Spaces } & TEI & Area & FI \\
\hline Technical Zone & $-5,5$ & 141,0 & $-775,5$ \\
\hline Professor's Office & 0,1 & 724,9 & 72,5 \\
\hline Classroom & $-2,5$ & 804,1 & $-2010,3$ \\
\hline Auditorium & -3 & 250,7 & $-752,1$ \\
\hline $\begin{array}{l}\text { Sanitary } \\
\text { Installations }\end{array}$ & $-8,4$ & 159,6 & $-1340,6$ \\
\hline Cafeteria & $-4,7$ & 15,1 & $-71,0$ \\
\hline Laboratory & 0,8 & 307,5 & 246,0 \\
\hline Offices & $-5,2$ & 701,3 & $-3646,8$ \\
\hline $\begin{array}{l}\text { Ala Autónoma's } \\
\text { Total }\end{array}$ & & 3104,2 & $-8277,7$ \\
\hline
\end{tabular}

This scenario has as important point, the fact that the FI of the Ala Autónoma decreases significantly, almost $19 \%$. This is due to the fact that this analysis works with a different scale than usual, being more restrictive in its perception and, consequently, making the factors of each space have a lower score than in the initial analysis. Consequently, the final TEI will be smaller, as shown in the table.

Another point to note is that the common room and the classroom are still very representative in the total scenario, corresponding to $68.4 \%$ of the total building FI.

This last scenario, Energy Scenario, differs from the others for several reasons, but the main one is the fact that it works based on a future idea of university projects. One of the main points is that the university has in its planning schedule, an already approved project for the installation of photovoltaic panels to capture solar energy and generate electricity for the whole institution.

The initial principle of the analysis of this scenario is to understand how the improvement of the electric energy scenario by being the most significant impact according to this investigation, can be perceived.

Below you can see the difference of TEIs from the initial scenario and the energy scenario:
Table 7. Comparation between Scenarios

\begin{tabular}{|l|l|l|l|}
\hline \multicolumn{2}{|c|}{ Initial Scenario } & \multicolumn{2}{c|}{ Energy Scenario } \\
\hline Factors & TEI & Factors & TEI \\
\hline Energy Usage & $-18,8$ & Energy Usage & $-9,6$ \\
\hline
\end{tabular}

Here it sees how the change in the factors of the analysis of all spaces, show that with the implementation of the photovoltaic panels at the university the environmental impact will demonstrate a considerable change, going from a TEI from -18.8 to -9.6 . These points are important in the analysis by showing how acting on a determined impact alters the entire Final Impact of a building.

This confirmation can be seen below in which the FI of the Ala Autónoma has changed considerably, if compared with the other scenarios.

The table below shows the results obtained during the analysis.

Table 8. Result of FI by space (Energy Analyze).

\begin{tabular}{|l|c|c|c|}
\hline \multicolumn{1}{|c|}{ Spaces } & TEI & Area & FI \\
\hline Technical Zone & $-5,1$ & 141,0 & $-719,1$ \\
\hline Professor's Office & 0,7 & 724,9 & 507,4 \\
\hline Classroom & $-1,9$ & 804,1 & $-1527,8$ \\
\hline Auditorium & $-2,4$ & 250,7 & $-601,7$ \\
\hline $\begin{array}{l}\text { Sanitary } \\
\text { Installations }\end{array}$ & $-7,6$ & 159,6 & $-1213,0$ \\
\hline Cafeteria & $-4,1$ & 15,1 & $-61,9$ \\
\hline $\begin{array}{l}\text { Laboratory } \\
\text { Offices }\end{array}$ & $-4,4$ & 307,5 & 430,5 \\
\hline $\begin{array}{l}\text { Ala Autónoma's } \\
\text { Total }\end{array}$ & 701,3 & $-3226,0$ \\
\hline
\end{tabular}

When compared to the other scenarios, this one had the lowest FI. This can be seen that when the forces to minimize an impact are effectively concentrated and commitment is demonstrated, it is possible to perceive improvement in the building FI.

It is noteworthy in comparison with the other scenarios, as this one has less significant negative values and how, through this change, the positive impacts started to have higher values and to be more representative.

This is one of the points that supports the fact that the implementation of solar panels is important. It supports how environmentally this investment is significant for not only the area of study but for the entire university. 


\section{Conclusion}

First and objectively, the university, more precisely the building of the Ala Autónoma, possesses significant environmental impacts in its majority; although there are positive impacts, most of them are classified as negative. Therefore, it can be concluded initially that the TEI of the negative environmental impacts is higher than the TEI of the positive environmental impacts.

Among all the scenarios analysed, the best results of all were the energy scenario. This shows that working more and more specifically in a certain space is increasingly important for an improvement of the management system and environmental analysis. Moreover, the energy scenario showed an improvement of $43.4 \%$ of the FI of the initial scenario; therefore, when acting specifically on a given impact, it was shown to be very efficient in this type of analysis.

It can also be realized that, because the spaces with the largest FI are the Common Room and the Classroom, to act in the minimization of the main impact, the electric energy in these spaces, can be a crucial point to soften the environmental problems in the study area, mainly with short-term actions.

This analysis guarantees greater support for the university's project of photovoltaic panel's installations in the future; since it further reinforces that acting in minimizing an environmental impact is much more profitable and environmental better impacting.

This article also demonstrates the fact that acting in environmental mitigation in a more incisive, local, direct and precise way, demonstrates a great effectiveness, since the analysis of this particular scenario is the most promising of all.

In the future it is expected that the factors of analysis are increased and that other sustainability indicators are used to increase the precision and standard of the analysis. In this way, it is expected that this project can be worked in different environments and with a better evaluation.

On the other hand, the significance attributed to each type of impact in each distinct space must still be analysed through the attribution of attractiveness differences in multicriteria analysis models within focus group sessions. It will thus be possible to define weights that represent new, progressively more complete analysis scenarios

\section{References}

1. Dias. (2006). Gestão ambiental: Responsabilidade social e sustentabilidade. São Paulo, São Paulo, Brazil.

2. Rohrich. (2015). A Gestão Ambiental na Universidade Federal do Paraná: Um estudo de caso sobre a gestão ambiental e o gerenciamento de resíduo sno Campus Litoral. Paraná, Brazil.
3. Juliatto, C. J. (2011). Gestão Integrada de Resíduos Sólidos para instituições públicas de ensino superior. Magazine Gual, 170-193. Brazil.

4. Frank, Q. (2001). Desenvolvimento do Sistema de Gestão Ambiental da Universidade Regional de Blumenau. Blumenau, Brazil.

\section{HASAN, M., \& MORRISON, A. (2011). Current}

University Environmental Management Practices.

6. Rocha, C. P. (2005). Avaliação de impactos ambientais nos países do MERCOSUL. Ambiente\&Sociedade Magazine.

7. Ministery of Environment. (1986). Resolução CONAMA $n^{\circ} 1$. Diretrizes Gerais para a avaliação de impacto ambiental. Brasil. Source: http://www.mma.gov.br/port/conama/legislacao/CONA MA_RES_CONS_1986_001.pdf.

8. Portuguese Institute of Quality (2015). Norma Portuguesa. Sistema de gestão ambiental: Requisitos e linhas de orientação para a sua utilização (ISO 14001:2015. Caparica, Portugal.

9. Tauchen, B. (2006). A gestão ambiental em instituições de ensino superior: Modelo para implementação em campus universitário. Gestão e Produção, 2-14. Brazil. 